\title{
Front Matter: Volume 9912
}

, "Front Matter: Volume 9912," Proc. SPIE 9912, Advances in Optical and Mechanical Technologies for Telescopes and Instrumentation II, 991201 (12 October 2016); doi: 10.1117/12.2250986

Event: SPIE Astronomical Telescopes + Instrumentation, 2016, Edinburgh, United Kingdom 


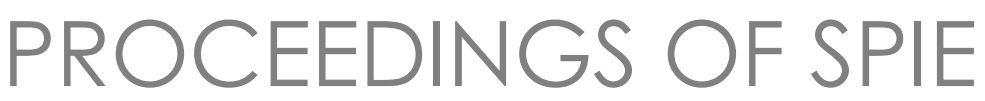

\title{
Advances in Optical and Mechanical Technologies for Telescopes and Instrumentation II
}

\author{
Ramón Navarro \\ James H. Burge \\ Editors
}

26 June - 1 July 2016

Edinburgh, United Kingdom

Sponsored by

SPIE

Cooperating Organizations

American Astronomical Society (United States) - Australian Astronomical Observatory (Australia) - Association of Universities for Research in Astronomy (AURA) • Canadian Astronomical Society (CASCA) (Canada) - Canadian Space Agency (Canada) • European Astronomical Society (Switzerland) • European Southern Observatory (Germany) • National Radio Astronomy Observatory • Royal Astronomical Society (United Kingdom) • Science \& Technology Facilities Council (United Kingdom)

Published by

SPIE

Volume 9912

Part One of Three Parts

Proceedings of SPIE 0277-786X, V. 9912

SPIE is an international society advancing an interdisciplinary approach to the science and application of light.

Advances in Optical and Mechanical Technologies for Telescopes and Instrumentation II, edited by Ramón Navarro, James H. Burge, Proc. of SPIE Vol. 9912, 991201

(C) 2016 SPIE · CCC code: 0277-786X/16/\$18 · doi: 10.1117/12.2250986 
The papers in this volume were part of the technical conference cited on the cover and title page. Papers were selected and subject to review by the editors and conference program committee. Some conference presentations may not be available for publication. Additional papers and presentation recordings may be available online in the SPIE Digital Library at SPIEDigitallibrary.org.

The papers reflect the work and thoughts of the authors and are published herein as submitted. The publisher is not responsible for the validity of the information or for any outcomes resulting from reliance thereon.

Please use the following format to cite material from these proceedings:

Author(s), "Title of Paper," in Advances in Optical and Mechanical Technologies for Telescopes and Instrumentation II, edited by Ramón Navarro, James H. Burge, Proceedings of SPIE Vol. 9912 (SPIE, Bellingham, WA, 2016) Six-digit Article CID Number.

ISSN: 0277-786X

ISBN: 9781510602038

ISSN: 1996-756X (electronic)

ISBN: 9781510602045 (electronic)

Published by

SPIE

P.O. Box 10, Bellingham, Washington 98227-0010 USA

Telephone +1 3606763290 (Pacific Time) · Fax +1 3606471445

SPIE.org

Copyright @ 2016, Society of Photo-Optical Instrumentation Engineers.

Copying of material in this book for internal or personal use, or for the internal or personal use of specific clients, beyond the fair use provisions granted by the U.S. Copyright Law is authorized by SPIE subject to payment of copying fees. The Transactional Reporting Service base fee for this volume is $\$ 18.00$ per article (or portion thereof), which should be paid directly to the Copyright Clearance Center (CCC), 222 Rosewood Drive, Danvers, MA 01923. Payment may also be made electronically through CCC Online at copyright.com. Other copying for republication, resale, advertising or promotion, or any form of systematic or multiple reproduction of any material in this book is prohibited except with permission in writing from the publisher. The CCC fee code is 0277-786X/16/\$18.00.

Printed in the United States of America.

Publication of record for individual papers is online in the SPIE Digital Library.

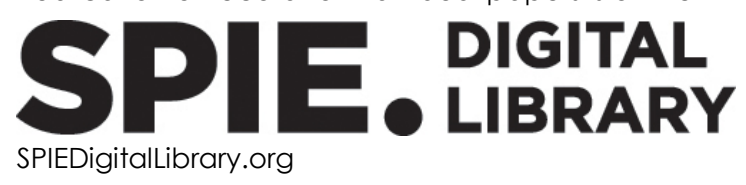

Paper Numbering: Proceedings of SPIE follow an e-First publication model. A unique citation identifier (CID) number is assigned to each article at the time of publication. Utilization of CIDs allows articles to be fully citable as soon as they are published online, and connects the same identifier to all online and print versions of the publication. SPIE uses a six-digit CID article numbering system structured as follows:

- The first four digits correspond to the SPIE volume number.

- The last two digits indicate publication order within the volume using a Base 36 numbering system employing both numerals and letters. These two-number sets start with 00, 01, 02, 03, 04, 05, 06, 07, 08, 09, OA, OB ... OZ, followed by 10-1Z, 20-2Z, etc. The CID Number appears on each page of the manuscript. 


\title{
Contents
}

\author{
xvii Authors \\ xxvii Conference Committee \\ xxxi Introduction
}

\section{Part One}

\section{SESSION 1 ATMOSPHERIC COMPENSATION}

991202 A prototype of the NFIRAOS to instrument thermo-mechanical interface [9912-1]

991203 Polarization dOTF: on-sky focal plane wavefront sensing [9912-2]

991204 Electromagnetic deformable mirror development at TNO [9912-3]

$991205 \quad$ NFIRAOS beamsplitters subsystems optomechanical design [9912-4]

\section{SESSION 2 SEGMENT MIRROR TECHNOLOGIES}

991206 Development and test of the Ball Aerospace optical frequency comb: a versatile measurement tool for aerospace applications [9912-5]

991207 A soft actuator for Prototype Segmented Mirror Telescope [9912-6]

991208 ZERODUR strength modeling with Weibull statistical distributions [9912-7]

991209 Development and final design of FAME active array [9912-8]

9912 OA Stressed mirror annular polishing for scale-down TMT primary segments [9912-9]

9912 OB Research on key technical issues of contact testing method for large diameter off-axis aspheric segments [9912-10]

\section{SESSION 3 OPTICAL FABRICATION}

$99120 \mathrm{C}$ Technique for diamond machining large ZnSe grisms for the Rapid Infrared/Imager Spectrograph (RIMAS) [9912-11]

9912 OD Polishing techniques for MEGARA pupil elements optics [9912-12]

9912 OE A large size ion beam figuring system for $1.2 \mathrm{~m}$ astronomical telescopes fabrication [9912-13] 
9912 OF Manufacturing of super-polished large aspheric/freeform optics [9912-14]

$99120 \mathrm{~F}$ Freeform and advanced optics for ELT instrumentation [9912-15]

SESSION 4 MATERIALS

$99120 \mathrm{~J}$ ZERODUR thermo-mechanical modelling and advanced dilatometry for the ELT generation (Invited Paper) [9912-18]

9912 OK Fused silica challenges in sensitive space applications [9912-19]

$9912 \mathrm{OL} \quad$ Manufacturing aspheric mirrors made of zero thermal expansion cordierite ceramics using Magnetorheological Finishing (MRF) [9912-20]

9912 OM Silicon carbide main structure for EUCLID NISP instrument in final development [9912-21]

\section{SESSION 5 LARGE OPTICS MANUFACTURING}

$991200 \quad$ Fabrication and testing of $4.2 \mathrm{~m}$ off-axis aspheric primary mirror of Daniel K. Inouye Solar Telescope [9912-23]

9912 OP New and improved technology for manufacture of GMT primary mirror segments [9912-24]

$99120 Q \quad$ Polishing and testing of the $3.4 \mathrm{~m}$ diameter $\mathrm{f} / 1.5$ primary mirror of the INO telescope [9912-25]

9912 OR Modern technologies of fabrication and testing of large convex secondary mirrors [9912-26]

9912 OS Advanced Mirror Technology Development (AMTD) project: overview and year four accomplishments [9912-27]

9912 OU Thin glass shells for AO: from plano to off-axis aspherics [9912-29]

9912 OV Status of mirror segment production for the Giant Magellan Telescope [9912-30]

9912 OX Manufacture and final tests of the LSST monolithic primary/tertiary mirror [9912-32]

\section{SESSION 6 TEST AND METROLOGY I}

9912 OY Large aperture freeform VIS telescope with smart alignment approach [9912-33]

$99120 Z$ Effects of thermal inhomogeneity on 4m class mirror substrates [9912-34]

991210 Unmanned aerial vehicles in astronomy [9912-35]

991211 Coordinate metrology of a primary surface composite panel from the Large Millimeter Telescope [9912-36] 
991212 Error analysis of back focal length measurement technique for long focus large-scaled lenses [9912-37]

\section{SESSION 7 TEST AND METROLOGY II}

991213 Evaluation of novel approach to deflectometry for high accuracy optics [9912-38]

991214 Laboratory and field testing results of the LMT/GTM primary surface actuators [9912-39]

991215 Optical tests of the Si immersed grating demonstrator for METIS [9912-41]

\section{SESSION 8 TECHNOLOGIES FOR CRYOGENIC INSTRUMENTS}

991216 Optical performance analysis and test results of the EUCLID near-infrared spectrophotometer [9912-42]

991217 GMTIFS: the adaptive optics beam steering mirror for the GMT integral-field spectrograph [9912-43]

991218 Development of superconducting voice coil motor of a cold chopper for MICHI [9912-44]

99121 A Characterization of the actuator of EMIR configurable slit unit [9912-46]

9912 1B A cryogenic 'set-and-forget' deformable mirror [9912-47]

\section{SESSION 9 TELESCOPE STRUCTURES AND DOMES}

$99121 \mathrm{C}$ Local seeing determination by thermal-CFD analysis to optimize the European Solar Telescope image quality [9912-48]

9912 1D Initial development of high-accuracy CFRP panel for DATE5 antenna [9912-49]

$99121 \mathrm{E} \quad$ Completely open-foldable domes remaining cool in sunshine [9912-50]

$99121 \mathrm{~F} \quad$ New isostatic mounting concept for a space born Three Mirror Anastigmat (TMA) on the Meteosat Third Generation Infrared Sounder Instrument (MTG-IRS) [9912-51]

$99121 \mathrm{G}$ Analytical optimization and test validation of the submicron dimensional stability of the CHEOPS space telescope's CFRP structure [9912-52]

SESSION 10 ACTIVE INSTRUMENTS (ACTIVE STRUCTURES, ACTIVE OPTICS)

$99121 \mathrm{H}$ Developments in active optics for space instruments: an ESA perspective [9912-53]

991211 FAME: freeform active mirror experiment [9912-54]

$99121 \mathrm{~J} \quad$ Novel and efficient ADC concept for BlackGEM telescope [9912-55] 
$99121 \mathrm{~K}$ Multilayer active shell mirrors for space telescopes [9912-56]

$99121 \mathrm{~N} \quad$ Long-term stable active mount for reflective optics [9912-59]

\section{SESSION 11 OPTICAL FIBERS AND POSITIONERS I}

991210 Multicore fibre technology: the road to multimode photonics [9912-60]

$99121 \mathrm{P} \quad$ A microlens-array based pupil slicer and double scrambler for MAROON-X [9912-61]

9912 IR 12.5-GHz-spaced laser frequency comb covering $\mathrm{Y}, \mathrm{J}$, and $\mathrm{H}$ bands for infrared Doppler instrument [9912-63]

9912 is Design of real-time measurement for optical fiber positioning based on FPGA [9912-64]

\section{SESSION 12 OPTICAL FIBERS AND POSITIONERS II}

$99121 \mathrm{~T} \quad$ Optimal non-circular fiber geometries for image scrambling in high-resolution spectrographs [9912-192]

$99121 \mathrm{~V}$ Communication architecture system for fiber positioning of DESI spectrograph [9912-66]

9912 IW TAIPAN instrument fibre positioner and Starbug robots: engineering overview [9912-67]

$99121 \mathrm{X}$ Pupil slicer design for the NASA-NSF extreme precision Doppler spectrograph concept WISDOM [9912-183]

991212 Post-inscription tuning of multicore fiber Bragg gratings [9912-69]

\section{SESSION 13 MULTI OBJECT SPECTROSCOPY}

991220 First results of tests on the WEAVE fibres [9912-70]

991221 Echidna Mark II: one giant leap for 'tilting spine' fibre positioning technology [9912-71]

991222 The Potsdam MRS spectrograph: heritage of MUSE and the impact of cross-innovation in the process of technology transfer [9912-72]

991223 TAIPAN fibre feed and spectrograph: engineering overview [9912-73]

\section{SESSION 14 SLIT SPECTROSCOPY AND IMAGE SLICERS}

991225 Fabrication of a wide-field NIR integral field unit for SWIMS using ultra-precision cutting [9912-75]

991226 Stop-less Lyot coronagraph for exoplanet characterization: first on-sky validation in VLT/SPHERE [9912-76] 
991227 Development of an efficient photonic device for the reformatting of celestial light [9912-77]

\section{Part Two}

SESSION $14 \quad$ SLIT SPECTROSCOPY AND IMAGE SLICERS (CONT.)

991228 Modal noise characterisation of a hybrid reformatter [9912-78]

991229 A rubidium traced white-light etalon calibrator for MAROON-X [9912-79]

SESSION 15 COATINGS, FILTERS AND GRATINGS I

9912 2A New grating concepts in the NIR and SWIR spectral band for high resolution earthobservation spectrometers [9912-80]

9912 2B Characterizing the cross dispersion reflection gratings of CRIRES+ [9912-81]

9912 2C Final design and choices for EUCLID NISP grism [9912-82]

\section{SESSION 16 COATINGS, FILTERS AND GRATINGS II}

$99122 \mathrm{E} \quad$ Advances in far-ultraviolet reflective and transmissive coatings for space applications [9912-84]

$99122 \mathrm{~F}$ Use of plasma enhanced ALD to construct efficient interference filters for astronomy in the FUV [9912-85]

$99122 \mathrm{G}$ Update on UCO's advanced coating lab development of silver-based mirror coatings [9912-86]

$99122 \mathrm{H} \quad$ Advanced astronomical filter design: challenges, strategy, and results to meet current and future requirements [9912-87]

$991221 \quad$ Advanced optical coatings for astronomical instrumentation [9912-88]

\section{SESSION 17 CORONOGRAPHY AND HIGH CONTRAST IMAGING}

9912 2K Mathematical and computational modeling of a ferrofluid deformable mirror for highcontrast imaging [9912-90]

$99122 \mathrm{~L} \quad$ Apodized vortex coronagraph designs for segmented aperture telescopes [9912-91]

9912 2M Digital adaptive coronagraphy using SLMs: promising prospects of a novel approach, including high-contrast imaging of multiple stars systems [9912-92] 
991220 Precision optical edges for a starshade external occulter [9912-94]

POSTER SESSION: COATINGS, FILTERS AND GRATINGS

$99122 \mathrm{R}$ Revisiting static modulation in pyramid wavefront sensing [9912-95]

9912 2T J-Black: a stray light coating for optical and infrared systems [9912-98]

$99122 \mathrm{~A} \quad$ Atomic Layer Deposited (ALD) coatings for future astronomical telescopes: recent developments [9912-99]

$99122 \mathrm{~V}$ Astronomical large Ge immersion grating by Canon [9912-100]

$9912 \mathrm{~W}$ The legacy of filter design and how that has extended into current choices for advanced astronomical filter [9912-101]

$99122 \mathrm{X}$ Mid-infrared transmission gratings in chalcogenide glass manufactured using ultrafast laser inscription [9912-102]

$99122 Y$ Thin-film optical pass band filters based on new photo-lithographic process for CaSSIS FPA detector on Exomars TGO mission: development, integration, and test [9912-103]

$99122 Z$ Novel diffraction gratings for next generation spectrographs with high spectral dispersion [9912-104]

991230 Manufacturing and coating of optical components for the EnMAP hyperspectral imager [9912-105]

991232 Performance characteristics of advanced volume phase holographic gratings for operation in the near infrared [9912-107]

991233 Strategies for single-point diamond machining a large format germanium blazed immersion grating [9912-108]

991234 Programmable CGH on photochromic material using DMD [9912-109]

991235 Cooled optical filters for Q-band infrared astronomy (15-40 $\mu \mathrm{m})$ [9912-110]

991237 A local attenuation filter for accurate photometry of near-infrared bright stars [9912-112]

991238 Characterization of an integrally wound tungsten and aluminum filament for physical vapor deposition [9912-113]

991239 Improved silver mirror coating for ground and space-based astronomy [9912-114]

$99123 \mathrm{~A}$ First results on narrow bandpass steep edge optical filters for the JST/T250 telescope instrumentation [9912-252]

9912 3B Photopolymer based VPHGs: from materials to sky results [9912-253] 
POSTER SESSION: MATERIALS

9912 3D Transmission and opto-mechanical performance of the liquid lens coupling in the Robert Stobie Spectrograph on SALT [9912-115]

9912 3E Large optical glass blanks for the ELT generation [9912-116]

9912 3F ULE design considerations for a 3m class light weighted mirror blank for E-ELT M5 [9912-117]

$99123 \mathrm{G}$ High volume ULE segment production [9912-118]

$99123 \mathrm{H}$ Smart telescope for astronomy [9912-120]

$991231 \quad$ Advanced structural design for precision radial velocity instruments [9912-121]

9912 3K ESPRESSO optical bench: from mind to reality [9912-123]

POSTER SESSION: OPTICAL FABRICATION

$99123 \mathrm{~L} \quad$ Approaching perfection in the manufacturing of silicon immersion gratings [9912-124]

$99123 \mathrm{M}$ Towards freeform curved blazed gratings using diamond machining [9912-125]

$99123 \mathrm{~N} \quad$ Nonconventional ultra-precision manufacturing of ULE mirror surfaces using atmospheric reactive plasma jets [9912-126]

991230 Vibrating membrane mirror concept for adaptive optics [9912-127]

$99123 \mathrm{P}$ A segmented subreflector with electroformed nickel laminated panels for the Large Millimeter Telescope [9912-128]

$99123 Q \quad$ Optimisation of grolishing freeform surfaces with rigid and semi-rigid tools [9912-129]

9912 3T Manufacturing methods of testing the large-sized optics at the stage of grinding, aspherical surface centering, and interface elements positioning before gluing [9912-132]

$99123 \mathrm{U}$ Studying the stability of Astrositall thermal and mechanical properties while manufacturing the astronomical and space mirrors [9912-133]

$99123 \mathrm{~V}$ Diamond fly cutting of aluminum thermal infrared flat mirrors for the OSIRIS-REx Thermal Emission Spectrometer (OTES) instrument [9912-134]

9912 3W Combined fabrication technique for high-precision aspheric optical windows [9912-135]

$99123 X \quad$ Process optimization of laser-based solderjet bumping for the mounting of optical components [9912-136]

$99123 Y$ Every photon counts: improving low, mid, and high-spatial frequency errors on astronomical optics and materials with MRF [9912-137] 
991232 Process improvements in the production of silicon immersion gratings [9912-138]

991240 Aspherical mirrors for the Gamma-ray Cherenkov Telescope, a Schwarschild-Couder prototype proposed for the future Cherenkov Telescope Array [9912-140]

991241 Development of the fast steering secondary mirror assembly of GMT [9912-141]

991244 Results from bonding of the SALT primary mirror edge sensors [9912-144]

991245 Manufacturing process for the WEAVE prime focus corrector optics for the $4.2 \mathrm{~m}$ William Hershel Telescope [9912-254]

991246 Aspherization of off-axis high-asphericity mirrors with arbitrary external circuit by means of CNC machines [9912-255]

$991247 \quad$ Euclid mirrors and test collimator: AMOS developments [9912-256]

991248 Investigation of four classical groove patterns with three typical tool types for use in the rigid tool smoothing process [9912-273]

POSTER SESSION: TEST AND METROLOGY

9912 4C The influence of technological mounting of lightweight large size space astronomical mirrors into the shape of its reflecting surface during interferometric control [9912-148]

9912 4D MEGARA: large pupil element tests and performance [9912-149]

$99124 \mathrm{E}$ Thermal testing results of an electroformed nickel secondary (M2) mirror [9912-150]

9912 4F Mapping the Large Millimeter Telescope primary reflector using photogrammetry: a first comparison with $12 \mathrm{GHz}$ holography [9912-151]

$99124 \mathrm{H} \quad$ Low-cost measurement and monitoring system for cryogenic applications [9912-153]

991241 Three-dimensional metrology inside a vacuum chamber [9912-154]

$99124 \mathrm{~J}$ The alidade temperature behaviour of TM65m antenna and its effects on pointing accuracy [9912-157]

$99124 \mathrm{~K}$ Hollow-cathode lamps as optical frequency standards: the influence of optical imaging on the line-strength ratios [9912-158]

9912 4L Alignment of the ESPRESSO Coudé train on the ESO VLT [9912-159]

$991240 \quad$ VUV optical ground system equipment and its application to the ICON FUV flight grating characterization and selection [9912-162]

$99124 \mathrm{P}$ Singular values behaviour optimization in the diagnosis of feed misalignments in radioastronomical reflectors [9912-163] 
$99124 \mathrm{~V}$ Tolerancing of a carbon fiber reinforced polymer metering tube structure of a highresolution space-borne telescope [9912-169]

$99124 \mathrm{~W} \quad$ TCS and peripheral robotization and upgrade on the ESO 1-meter telescope at La Silla Observatory [9912-170]

$99124 \mathrm{X}$ Error compensation research on the focal plane attitude measurement instrument [9912-171]

\section{Part Three}

\section{POSTER SESSION: TELESCOPE STRUCTURES AND DOMES (CONT.)}

$99124 \mathrm{Y} \quad$ Research and implementation of the integrated cooling system for focal plate [9912-172]

$99124 Z$ Performance of the Gamma-ray Cherenkov Telescope structure: a dual-mirror telescope prototype proposed for the future Cherenkov Telescope Array [9912-173]

991253 Development of a $\mathbf{0 . 5 m}$ clear aperture Cassegrain type collimator telescope [9912-259]

POSTER SESSION: OPTICAL FIBERS AND POSITIONERS

991255 On the origin and removal of interference patterns in coated multimode fibres [9912-177]

991256 Effects of fiber manipulation methods on optical fiber properties [9912-178]

991257 Influence of misalignment on output of astronomical large-core fibers of multi-object fiber spectroscopic telescopes [9912-179]

991258 Back-illuminate fiber system research for multi-object fiber spectroscopic telescope [9912-180]

991259 A compact optical fiber positioner [9912-181]

$99125 \mathrm{~A}$ Research of subdivision driving technology for brushless DC motors in optical fiber positioning [9912-182]

9912 5B Pupil Scrambling Integral Field Unit (PSI) for the Robert Stobie Spectrograph on SALT [9912-184]

9912 5C Characterizing octagonal and rectangular fibers for MAROON-X [9912-185]

9912 5E A new miniaturized fiber positioning node for LAMOST [9912-187]

9912 5F A new modular guidance system for the Southern African Large Telescope [9912-188] 
$99125 \mathrm{G}$ Design, development, and performance of the fibres of MOONS [9912-189]

$99125 \mathrm{H} \quad$ PEPSI-feed: linking PEPSI to the Vatican Advanced Technology Telescope using a 450m long fibre [9912-190]

991251 Design of multi-motor distributed control system for optical fibers positioning based on CAN bus [9912-191]

9912 5J High numerical aperture multimode fibers for prime focus use [9912-193]

9912 5K A 24mm diameter fibre positioner for spectroscopic surveys [9912-267]

\section{POSTER SESSION: TECHNOLOGY FOR SPECTROSCOPY}

9912 5L MEGARA: high-precision alignment system for gluing fibers and microlenses [9912-194]

$99125 \mathrm{M}$ Shock and vibration testing of digital micromirror devices (DMDs) for space-based applications [9912-195]

$99125 \mathrm{~N} \quad$ Development of an optical device (Field Stacker) for achieving accurate photometry in ground-based mid-infrared observations [9912-196]

$991250 \quad$ Multi-resolution waveguide image slicer for the PEPSI instrument [9912-197]

9912 5P Opto-mechanical design of an image slicer for the GRIS spectrograph at GREGOR [9912-198]

$99125 Q \quad$ Performance estimates for spectrographs using photonic reformatters [9912-199]

$99125 R \quad$ Collimating slicer for optical integral field spectroscopy [9912-201]

$99125 S$ Spectral slicing for METIS: an efficient alternative to cross-dispersion [9912-202]

$99125 \mathrm{~T}$ A trial production of a large format image slicer unit for a possible future mid-infrared instrument on the TMT [9912-203]

$99125 \mathrm{U}$ Measurements of the reflectance, contrast ratio, and scattering properties of digital micromirror devices (DMDs) [9912-268]

$99125 \mathrm{~V}$ Optical evaluation of digital micromirror devices (DMDs) with UV-grade fused silica, sapphire, and magnesium fluoride windows and long-term reflectance of bare devices [9912-269]

$99125 \mathrm{~W}$ The effects of heavy ion radiation on digital micromirror device performance [9912-270]

$99125 \mathrm{X}$ On-sky performance evaluation and calibration of a polarization-sensitive focal plane array [9912-74] 
POSTER SESSION: TECHNOLOGIES FOR CRYOGENIC INSTRUMENTS

$99125 \mathrm{Y}$ How to achieve ultra-clean detectors and cryostats at astronomical instruments: measures to avoid contamination and dust on CCD detectors [9912-204]

$99125 Z$ Development of a cryogenic FTIR system for measuring very small attenuation coefficients of infrared materials [9912-205]

991260 Gluing interface qualification test results and gluing process development of the EUCLID near-infrared spectro-photometer optical assembly [9912-206]

991261 Final design of the grism cryogenic mount for the Euclid-NISP mission [9912-207]

991262 CARMENES-NIR channel spectrograph cooling system AIV: thermo-mechanical performance of the instrument [9912-208]

991263 New cryogenic temperature monitor: PLT-HPT-32 [9912-209]

991264 GMTIFS: cryogenic rotary mechanisms for the GMT Integral-Field Spectrograph [9912-210]

991265 Developing a long duration ${ }^{3} \mathrm{He}$ fridge for the LSPE-SWIPE instrument [9912-211]

991266 Sorption-cooled continuous miniature dilution refrigeration for astrophysical applications [9912-212]

POSTER SESSION: ACTIVE INSTRUMENTS (ACTIVE STRUCTURES, ACTIVE OPTICS)

991267 Smart warping harnesses for active mirrors and stress polishing [9912-214]

991268 Control system for an alternative actuator for the primary surface of the Large Millimeter Telescope (LMT/GTM) [9912-215]

991269 Thermal expansion as a precision actuator [9912-216]

99126 A Realization and testing of an active mirror mechanism for in-field pointing in eLISA [9912-217]

$99126 \mathrm{~B}$ Focal plane actuation by hexapod for the development of a high-resolution suborbital telescope [9912-218]

9912 6C Mechanical development of an alternative set of actuators for the LMT/GTM primary surface outer rings: also useful to replace the interim actuators [9912-219]

9912 6D The WEAVE focus translation system: from design to construction [9912-220]

$99126 \mathrm{~F}$ Active optics system for the $4 \mathrm{~m}$ telescope of the Eastern Anatolia Observatory (DAG) [9912-223] 
POSTER SESSION: CORONOGRAPHY AND HIGH CONTRAST IMAGING

$99126 \mathrm{G}$ A three-layer eight-octant phase mask towards broadband high-contrast observations [9912-224]

$99126 \mathrm{H} \quad$ Advances in starshade technology readiness for an exoplanet characterizing science mission in the 2020's [9912-225]

991261 Development of speckle nulling technique for the Savart-plate lateral-shearing interferometric nuller for exoplanets (SPLINE) [9912-226]

$99126 \mathrm{~J}$ Development and characterization of Four-Quadrant Phase Mask coronagraph (FQPM) [9912-227]

$99126 \mathrm{~K}$ Analysis of nulling phase functions suitable to image plane coronagraphy [9912-228]

$99126 \mathrm{~L}$ Development of PIAA Complex Mask Coronagraphs for large aperture ground-based telescopes [9912-230]

$99126 \mathrm{M}$ WFIRST/AFTA coronagraph contrast performance sensitivity studies: simulation versus experiment [9912-262]

$99126 \mathrm{~N}$ Design and construction of a 76m long-travel laser enclosure for a space occulter testbed [9912-272]

POSTER SESSION: ATMOSPHERIC COMPENSATION AND POLARIMETRY

9912 6Q CHOUGH: petite ADC for a high-order adaptive optics system [9912-234]

9912 6S Daytime sky polarization calibration limitations [9912-237]

9912 6T Progress in modeling polarization optical components for the Daniel K. Inouye Solar Telescope [9912-238]

$99126 \mathrm{U}$ Polarization modeling and predictions for DKIST part 1: telescope and example instrument configurations [9912-239]

$99126 \mathrm{~V} \quad$ An efficient stable optical polariser module for calibration of the S4UVN earth observation satellite [9912-263]

POSTER SESSION: REVOLUTIONARY TECHNOLOGIES

$99126 \mathrm{~W} \quad$ Noise modeling and analysis of an IMU-based attitude sensor: improvement of performance by filtering and sensor fusion [9912-240]

$99126 \mathrm{X} \quad$ Photocontrolled deformable mirrors as potential technology for astronomical instrumentation [9912-241]

$99126 \mathrm{Y}$ Low cost photonic comb for sub-m/s wavelength calibration [9912-242] 
$99126 Z$ An astro-comb calibrated solar telescope to search for the radial velocity signature of Venus [9912-243]

991270 NASA's Physics of the Cosmos and Cosmic Origins programs manage Strategic Astrophysics Technology (SAT) development [9912-244]

991271 Development of high-resolution arrayed waveguide grating spectrometers for astronomical applications: first results [9912-245]

991273 Auxiliary free space optical communication project to ensure continuous transfer of data for DAG the 4m telescope [9912-248]

991274 Adaptive optics fed single-mode spectrograph for high-precision Doppler measurements in the near-infrared [9912-249]

991277 Back-propagating the light of field stars to probe telescope mirrors aberrations [9912-264]

991278 Optimization of high sensitivity parametric transducers for the Gravitational Wave Detector "Mario Schenberg" [9912-265]

991279 The reconnaissance and early-warning optical system design for dual field of spacebased "solar blind ultraviolet" [9912-266] 
Proc. of SPIE Vol. $9912991201-16$

Downloaded From: https://www.spiedigitallibrary.org/conference-proceedings-of-spie on 25 Apr 2023 Terms of Use: https://www.spiedigitallibrary.org/terms-of-use 


\title{
Authors
}

Numbers in the index correspond to the last two digits of the six-digit citation identifier (CID) article numbering system used in Proceedings of SPIE. The first four digits reflect the volume number. Base 36 numbering is employed for the last two digits and indicates the order of articles within the volume. Numbers start with 00, 01, 02, 03, 04, 05, 06, 07, 08, 09, OA, OB...0Z, followed by 10-1Z, 20-2Z, etc.

\author{
A. G., Sreejith, 6W \\ Abchiche, A., $4 Z$ \\ Abdulkadyrov, Magomed A., 12, 3T, 3U, 46 \\ Abreu, Manuel, 4L \\ Abril, M., 62 \\ Abrams, Don Carlos, 20, 45, 6D \\ Adkins, Michael, 06 \\ Aftab, Maham, OF \\ Agócs, Tibor, 09, 15, 11, 45 \\ Aguiar, O. D., 78 \\ Aguiar-González, M., 63 \\ Aguirre, D., OD \\ Aitink-Kroes, Gabby, 09, 11, 67 \\ Akaiwa, Natsumi, 6G \\ Alata, Romain, 34 \\ Aliverti, Matteo, 3H, 4L \\ Allington-Smith, Jeremy R., 27, 28 \\ Alongi, Chris, 41 \\ Amado, P., 62 \\ Amans, Jean-Philippe, 4Z, 5G \\ Anaclerio, Enzo, 14 \\ Angel, J. R. P., OX \\ Angeli, G. Z., OX \\ Anretar, Alain, OU \\ Antelme, Jean-Pierre, OU \\ Anwand-Heenwart, Heiko, 2B \\ Aoki, W., $2 Z$ \\ Apodaca, R., 74 \\ Arasaki, Takayuki, $5 z$ \\ Arizmendi Reyes, Edgar, 11 \\ Arnold, Matthew, 3F \\ Arnold, Thomas, $3 \mathrm{~N}$ \\ Arns, James A., 32 \\ Arriaga, J., OD \\ Arrillaga, X., 5L \\ Arriola, Alexander, 27, 28 \\ Arroyo, J. M., OD \\ Arteaga-Magaña, César, 14, 68, 6C \\ Asano, Kentaro, $5 \mathrm{~N}$ \\ Atwood, Jenny, 05 \\ Aube, H., 5L \\ Avila, Gerardo, 4L, 5G \\ Aznárez, José A., 2E \\ Baba, Naoshi, 6G, 61 \\ Bach, Vinh, 6H \\ Baeten, Max, 04 \\ Baiges, J., $1 \mathrm{C}$ \\ Bakovic, M., 74 \\ Balasubramanian, Kunjithapatham, $6 \mathrm{~N}$
}

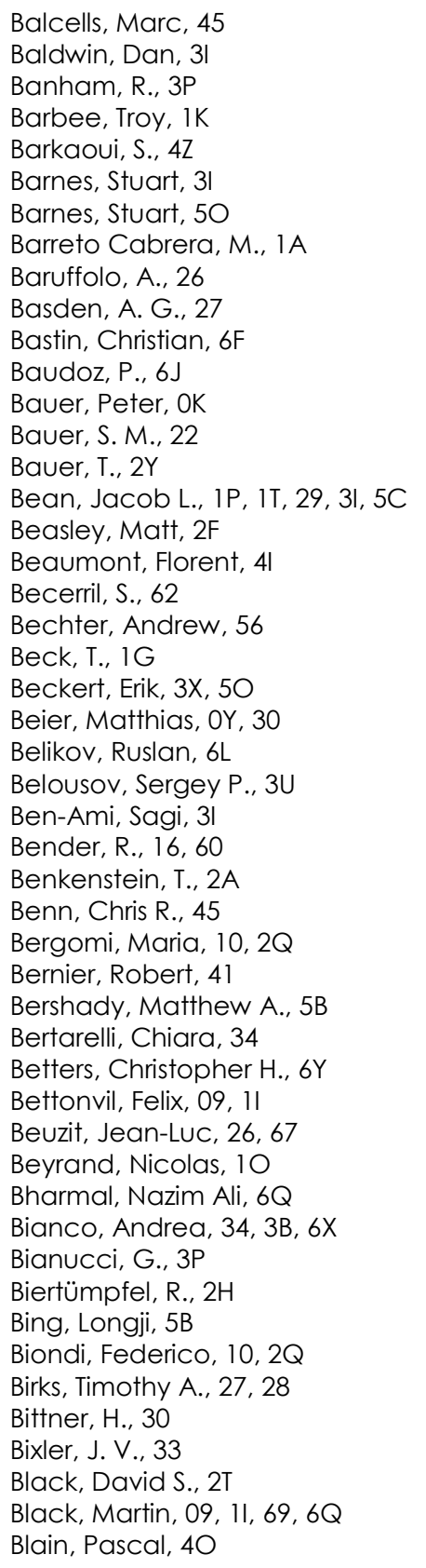


Blanc, Thomas, $6 Y$

Blanchard, P., 26

Bland-Hawthorn, Joss, 10, 12, 6Y, 71

Blecha, L., $1 G$

Bleuler, Hannes, 5K

Bloxham, Gabe, 17, 64

Bode, A., 16

Böhm, Georg, 3N

Bolte, Michael J., 2G

Bonafous, M., 6J

Bonifacio, Piercarlo, 20, 45, 6D

Bonora, Stefano, 6X

Boucher, Marc-André, 05

Bougoin, M., OM

Bourgenot, C., 3M

Bouri, Mohamed, 5K

Bourquin, $\mathrm{S}$., 2H, $3 \mathrm{~A}$

Bousquet, J. J., $4 Z$

Boussaha, F., 6J

Boz, Robert, 17, 64

Bradford, Samuel Case, $1 \mathrm{~K}, 6 \mathrm{H}$

Brady, A., IN

Bramall, David, 6V

Brandl, Bernhard R., 15, 1B

Brauneck, U., 2H, 2W, 3A

Brennan, Patricia, 3 I

Brink, Janus D., 3D, 5F

Brinkers, Sanneke, 04

Bristow, Paul, 2B

Brock, Neal, 5X

Broeg, C., $1 G$

Brooks, Cynthia B., 3L, $3 Z$

Brooks, Keira J., 03

Brown, David M., IW

Brown, Rebecca, 1W, 23

Browne, Keith, 5F

Brownsword, Richard A., 2X

Buchholtz, G., 4 Z

Buchschacher, Nicolas, $6 Z$

Budynkiewicz, Jamie, 31

Bundy, Dave, 17, 64

Burgal, José Alonso, 6D

Burge, James H., OF, OO, OP, OR, OV, OX

Burkhardt, Diana, 3X

Burkhardt, Thomas, $3 X$

Butcher, Helen L., 2X

Buteau-Vaillancourt, Louis, 05

Byrnes, Peter W. G., 02, 05

Caballero, J. A., 62

Cabral, Alexandre, 4L

Cabrera Cuevas, Lizeth, 11,4E, 4F

Caillat, Amandine, 26, 2C, 61

Caillon, Stéphane, OU

Calcines, Ariadna, 6V

Calisse, Paolo G., 66

Cameron, Andrew Collier, $6 Z$

Canchado, Manuel, 6D

Canestrari, Rodolfo, 13

Capobianco, Gerardo, 2E

Capone, John I., OC
Capozzoli, Amedeo, 4P

Carballo, C., OD

Cárdenas, C., 62

Carle, Michael, 26, 4 I

Carlotti, Alexis, 6K

Carolo, Elena, 10

Carrasco, Esperanza, 0D, 20, 45, 4D, 5L

Casalta, Joan Manel, 6D

Case, Scott, 1W, 23

Castel, D., OM

Castro Santos, David, 11, 4E, 4F

Catala, Laure, 03

Cavaller, L., $1 C$

Cecconi, Massimo, 6 Z

Cedazo, R., 5L

Ceria, W., OM

Cessa, V., $1 G$

Chadwick, P., 40

Challita, Zalpha, 11, 67

Charbonneau, David, 6 Z

Châteauneuf, François, 05

Cheleden, Spencer, 2G

Chen, Kunxing, OA

Chen, Zhe, OB

Cheng, Jingquan, ID

Cheng, Lixuan, $4 Y$

Cho, Myung K., 41

Chou, Cathy, 40

Choudhury, Debaditya, 27, 28

Chu, Jiaru, 4Y, 58, 59

Chun, Mark R., 5T

Chun, Moo-Young, 31

Churilov, Vladimir, 23

Cochrane, Dave, 45

Codina, R., 1C

Codona, Johanan L., 03

Coelho, Joao Pinto, 4L

Cola, Marcel, 47

Collados, M., 1C, 5P

Colless, James I., 6 Y

Connor, Peter, 45

Conroy, Charlie, 31

Content, Robert, 1W, 23

Coppens, Tonny, 15

Coppi, Gabriele, 65, 66

Cosentino, Rosario, $6 \mathrm{Z}$

Costille, Anne, 26, 2C, 4I, 61, 67

Cottard, H., $1 \mathrm{G}$

Courbin, F., 77

Coutts, D. W., 74

Cowley, David, 2G

Cozar Castellano, Juan, 63

Crane, Jeffrey D., 31

Crass, Jonathan, 56

Crause, Lisa, 3D

Crawford, Steven M., 03

Cremonese, G., $2 Y$

Criddle, Josephine, OK

Cruz, E., OD

Cuby, Jean-Gabriel, 67

xviii

Proc. of SPIE Vol. $9912991201-18$ 
Cui, Xiangqun, 57

Cumani, Claudio, 2B

Cunningham, Colin R., 2X

Curcio, Claudio, 4P

Cvetojevic, N., 74

Da Deppo, V., $2 Y$

Dagenais, Mario, 71

Dalton, Gavin B., 20, 21, 45, 6D

Damm, C., 1N, 30

Dangeon, L., $4 Z$

Darudi, Ahmad, OQ

Davies, John, 17, 64

Davis, Jonathan M., OP, OV

de Bernardis, Paolo, 65

De la Luz, J. A., OD

Dee, Kevin M., 20, 45, 6D

Deelen, Sander, $1 \mathrm{E}$

Deiries, S., 5 Y

Delabre, Bernard, 4L

Delgado, José Miguel, 6D

Depagne, Éric, 3D

Deshmukh, Prasanna, 07

Desnoyers, Nichola, 05

Desselle, Richard, 40

Dettmann, Lee, 41

Di Carmine, E., $2 Y$

Dietrich, Volker, 3E

Dima, Marco, 10

Djotni, Karim, 35

Doelman, Niek, 04

Dohlen, Kjetil, 26, 67

Domken, Isabelle, 40

Dorent, Stéphane, 20

Dorn, Reinhold J., 2B

Dournaux, J. L., 40, 4 Z

Doyle, Jeffrey, 02

Dribusch, Christoph, 41

Dubin, Matt, OR

Dubowy, M., 16, 60

Ducret, F., OM

Dumas, D., 40, $4 Z$

Dumas, Paul, $3 Y$

Dumusque, Xavier, $6 Z$

Dunn, Christina, 3Q

DuPraw, Brian, 2G

Dussourd, Adrien, OU

Eberhardt, Ramona, $3 \mathrm{X}$

Ebizuka, N., $2 Z$

Echeverri, Dan, 6N

Eder, J., 3P

Edwards, Mary, 3F, 3G

Egan, Mark, IX

Eikenberry, S., 3M

Ekinci, Mustafa, 4V, 53

Eller, Brianna, 2F

Ellis, Simon, 10

Epps, Harland, 31

Erhard, M., 30

Espeland, Brady, 17, 64

Esteves, M. A., 5P
Estrada Herrera, P., 5P

Evans, Ian, 3l

Evans, Janet, 31

Fabron, Christophe, 4l

Fäcke, T., 3B

Farinato, Jacopo, 10, 2Q

Farkas, Szigfrid, 09, 11

Farkas, Zoltan, 3V

Fasola, Gilles, 20, $4 Z$

Febvre, A., OM

Fechner, T., 22

Feger, T., 74

Ferrari, M., 26

Ferreira, E. C., 78

Ferro, I., 62

Ficai Veltroni, I., $2 Y$

Fineschi, Silvano, 2E

Firminy, J., 6J

Fischer, Andreas, 1E

Fitzsimmons, Joeleff, 02

Flebus, Carlo, 47, 6F

Flügel-Paul, T., 2A

Fok, Sandy, 11

Follert, Roman, 2B

Fordham, Bart, 17, 64

Foster, Jeff, 3l

Foucaud, Guillaume, oU

Foulon, Benjamin, OM, 2C, 61

Fox, Andrew, 3F, 3G

France, Kevin, $2 \mathrm{U}$

Frater, Eric, OR

Frebel, Anna, 3l

Freudling, Maximilian, $1 \mathrm{~F}$

Frey, Harald U., 40

Fryauf, David M., $2 G$

Fu, Guangwei, 5B

Fu, Li, 4J

Fuhlrott, Wilko, OY

Fumi, Pierluigi, 14

Fürész, Gábor, $1 \mathrm{X}$

Fusco, T., 26

Gäbler, D., 30

Gabor, P., 5H

Gabriel, Eric, 6F

Gajjar, Hitesh, 44

Gal, C., 16, 60

Gale, David M., 11, 3P, 4E, 4F, 68

Galicher, R., 6J

Gallego, J., OD, 4D, 5L

Gallieni, Daniele, 14

Galvin, Michael, 6N

Gambicorti, L., $2 Y$

Ganel, Opher, 70

García-Vargas, M. L., 4D, 5L

Gardner, Paul, 41

Garrido, Javier, IV

Garzón López, F., 1A

Gatkine, Pradip, 71

Gaudemard, J., 4 Z

Gauron, Thomas, 31 
Gawlik, K., 16, 60

Gebhardt, Andreas, OY

Gendron, E., 27

Geng, Tao, 57

Geng, XU G., 4J

Génova-Santos, R., 63

Gerber, M., $2 Y$

Gers, Luke, 45

Geyl, Roland, OG, OU, 21

Ghedina, Adriano, 6 Z

Ghislanzoni, R., 3P

Giglia, Angelo, 2E

Gil de Paz, A., 0D, 4D, 5L

Gilbert, James, 21

Gimenez, J.-L., OM

Gironnet, J., 40, $4 Z$

Glasse, A. C. H., $5 S$

Glenday, Alex G., $6 z$

Glez-de-Rivera, Guillermo, IV

Glier, M., 30

Gloesener, Pierre, 47

Gluck, L., 26

Goble, William, 38

Godefroy, P., 22

Gómez Reñasco, M. F., 63

Gómez, J., 3K

Gong, Xuefei, OA

Goodwin, Michael, IW

Goy, M., 1 N

Gracia Temich, Félix, 4H, 5P

Grassin, Olivier, 1E

Graves, Logan R., OP

Gray, Caroline, $3 Q$

Greggio, Davide, 10, 2Q

Gressler, W., OX

Griesmann, Ulf, $3 Z$

Griffiths, Ian M., 2K

Grigas, Michelle M., 3L, 32

Grimm, Stephan, IT

Gris-Sánchez, Itandehui, 27, 28

Grivel, C., 1C, 5P

Groff, Tyler D., 2K

Groppi, Christopher E., 3V

Grunhut, Jason, 2B

Grupp, F., 16, 60

GU, Yonggang, 1S, 5A, 5E, $5 \mathrm{I}$

Gubbini, E., 16, 60

Guinouard, Isabelle, $5 G$

Gullieuszik, Marco, 10

Guo, Liang, 5E, $5 \mathrm{I}$

Gurevich, Y. V., 74

Guyon, Olivier, 6L, 74

Guzman, Dani, 3l

Hadipour, Mousa, 30

Haimerl, Andreas, 2B

Hallibert, Pascal, $1 \mathrm{H}$

Halverson, S. P., 74

Hammerschlag, Robert H., $1 \mathrm{E}$

Han, Huajie, $1 \mathrm{~S}$

Han, Jeong-Yeol, 41
Hao, Xufeng, 1D

Hare, Tyson, 3I

Harel, Emmanuelle, oU

Harnisch, Gerd, 50

Harrington, David M., 6S, 6T, 6U

Harris, Robert J., 27, 28, 5Q

Hart, John, 17, 64

Hartmann, Peter, 08

Hartung, Johannes, OY

Harzendorf, T., 2A

Hashimoto, N., $2 Z$

Hattori, T., $2 Z$

Hatzes, Artie, 2B

Hawkins, Gary J., 35

Haynes, R., 22

Haynes, Vic, 66

Haywood, Raphäelle, $6 Z$

Heap, Sara R., 5M, 5U, 5V, 5W

Heiter, Ulrike, 2B

Hénault, François, 5R, 6K

Hennessy, John, 2U

Henry, David M., 6Q

Hermovet, Maxime, $6 \mathrm{Y}$

Hernández, Ernesto, 6C

Hernández, M., OD

Hernández-Rebollar, José Luis, 14, 68, 6C

Hernández Ríos, Emilio, 11, 4F

Hernández Suárez, Elvio, 4H

Herrald, Nicholas, 17, 64

Herranz, J., 62

Herreros, José Miguel, 6D

Herriot, Glen, 02, 05

Hill, Alexis, 02, 05

Hinterschuster, Renate, 2B

Hiroe, Takashi, 18

Hirsch, Brian, 6H

Hobbs, Thomas, 3F, 3G

Hölck, Daniel, 6Q

Hollandt, Jörg, 2B

Holota, Wolfgang, OY

Honda, Mitsuhiko, 18, 5T

Hoogendoorn, Pieter W., 1E

Hoogeveen, Ruud W. M., 15

Hopkins, Andrew M., 1W, 23

Hörler, Philipp, 5K

Hornaff, Marcel, 3X, 50

Hosobata, T., $2 Z$

Hoyland, R., 63

$\mathrm{Hu}, \mathrm{HaO}, \mathrm{OE}, 3 \mathrm{~W}$

Hu, Hongzhuan, 4Y, 58, 59

Hu, Hui-jun, 79

$\mathrm{Hu}$, Yiwen, 71

Huang, Run, 00

Huepa, A., OD

Huet, J. M., 40, $4 Z$

Hughes, David H., 3P, 68

Hughes, I., 3K

Hugot, Emmanuel, 09, 11, 26, 67

Huke, Philipp, 4K

Hull, T., 2W 
Hulme, Stephen N., $5 \mathrm{~F}$

Human, Jet, 04, 6A

Icasio Hernández, Octavio, 11

Iglesias-Páramo, J., 0D, 4D, 5L

Ignatov, Aleksandr N., 12, 3U

Ikeda, Yuji, 5T, $5 Z$

Ilyin, I., $5 \mathrm{H}$

Ives, Derek J., 2B

Iwert, Olaf, 5Y

Izazaga, R., OD

Jackson, J. L., 33

Jackson, Kathryn, $1 \mathrm{~K}$

Jaffe, Daniel T., 3L, $3 Z$

Jaimes, G. L., OD

Jang, Bi-Ho, 3l

Jang, Jeong-Gyun, 3l

Janssen, Huub, 1B

Jaquet, M., 26

Järvinen, $\mathrm{A}$., $5 \mathrm{H}$

Jaskó, Attila, 09, 11, 45

Jaury, Hervé, oU

Jedamzik, Ralf, 0J, 0Z, 3E

Jégouzo, I., $4 Z$

Jende, R., 30

Jeong, Ueejeong, 41

Jewell, April D., 2 U

Jewell, Jeffery, $2 \mathrm{~L}$

$\mathrm{Ji}, \mathrm{BO}, \mathrm{OA}$

Jiang, Yong B., 4J

Jiang, ZiBo, OA, OB

Jin, Dong-dong, 79

Jonas, Graeme, 45

Jordán, Andres, 3l, 4W

Jovanovic, N., 74

Jun, Youra, 41

Jung, Yves, 2B

K., Nirmal, 6W

Kaci, Karim, $1 \mathrm{~V}$

Kaji, Sayumi, $5 Z$

Kalide, André, IT

Kalkowski, G., 2A

Kamizuka, Takafumi, 18, 5N

Kamm, Andreas, 1N, 3X

Kan, Yi, 5A

Kasdin, N. Jeremy, 2K, 6N

Kashiwagi, K., IR

Kataza, Hirokazu, 18, 5T

Kato, Natsuko M., 25

Kawahara, Hajime, 61

Kawakita, Hideyo, $5 Z$

Keinänen, Perttu, $0 Q$

Kelz, A., 22

Kemkar, P. M. M., 07

Kenworthy, Matthew A., 03

Kerber, Florian, 2B

Keskin, Onur, 73

Kiaeerad, Fatemeh, 11

Kidder, Benjamin T., 3L, $3 Z$

Kim, Dae Wook, OF, OO, OP, OV, OX

Kim, Ho-Sang, 41
Kim, Jihun, 31

Kim, Kang-Min, 31

Kim, Yunjong, 6N

Kinast, J., 30

Kingsley, J. S., OV, OX

Kintziger, Christian, 40

Kitagawa, Yutaro, 25

Kitamura, Tsuyoshi, 2V

Klammer, Jesko, 1F

Klauser, Urs, 1W, 23

Klein, Barbara, 2B

Kneib, Jean-Paul, 5K

Knight, Scott, 06

Kobayakawa, Yutaka, 25

Kobayashi, Naoto, $5 z$

Kobayashi, Nobuhiko P., 2G

Koeslag, Anthony R., 5F

Kokubo, T., IR

Kommers, Johannes N. M., IE

Komuro, Yusuke, 6G

Kondo, Sohei, $5 z$

Konishi, Masahiro, 25

Korhonen, Tapio, $0 Q$

Körner, Christian, $1 \mathrm{~F}$

Kos, Janez, 6Y

Kotani, Takayuki, 1R, 61

Kragt, Jan, $1 \mathrm{~J}$

Kronig, Luzius, 5K

Ksianzou, Viachaslau, 55

Kuehn, Kyler, 1W, 23

Kuhn, Jeffrey R., 6S

Kühn, Jonas, $2 M$

Kuiper, Stefan, 04

Kuisl, A., 16

Kunisch, Clemens, OJ, $0 Z$

Kurokawa, T., IR

Kutyrev, Alexander S., OC

Kuzmenko, Paul J., OC, 33

L. Aguerri, J. Alphonso, 20, 45, 6D

Labadie, Lucas, 5Q

Lambert, Andrew J., 30

Lambert, Sam, 02

Lamontagne, Frédéric, 05

Lange, N., $1 \mathrm{~N}$

Langlois, M., 26

Langner, Andreas, OK

Lanzoni, Patrick, 34

Laporte, Philippe, 20, 40, 4 Z

Larruquert, Juan I., $2 \mathrm{E}$

Latham, David W., 6 Z

Laurent, Florence, 5R

Lavail, Alexis, 2B

Law, K., OV, OX

Lawrence, Jon S., 10, 1W, 23, 74

Lázaro-Hernández, Josefina, 68, 6C

Lazzarini, Paolo, 14

Lee, David, 2X, 5G

Lee, Kyoung-Don, 41

Lee, Sungho, 41

Leitch, James, 06 
Lemared, Sabri, 11, 67

Le Mignant, D., 26

Lemke, Ulrike, $5 Q$

Lemmer, Aaron J., 2K

Leon-Huerta, Andrea, 11, 4F

Leon-Saval, Sergio G., 10, 1Z, 6Y

Leplan, Hervé, 2 l

Lesman, Dirk, $1 \mathrm{~J}$

Lewis, Ian, 20

Lhomé, Emilie, 20, 45

$\mathrm{Li}, \mathrm{BO}, \mathrm{OA}, \mathrm{OB}$

Li, Chih-Hao, 6 Z

Li, Hongyu, 3Q

$\mathrm{Li}$, Tiancheng, $5 \mathrm{I}$

Li, XinNan, OA, OB

Liang, M., OX

Liang, Yong Jun, $\mathrm{OB}$

Liccardo, V., 78

Liedtke, P., 4W

Lindley, Emma Y., 10, 12

Ling, Quan B., 4J

Liseno, Angelo, 4P

Lisman, Douglas, $2 \mathrm{O}, 6 \mathrm{H}, 6 \mathrm{~N}$

Little, Steve L., OC, 33

Liu, Guocheng, $1 \mathrm{~S}$

Liu, Yongjun, 57

Liu, Zhigang, 4X, 58, 59

Lizon, Jean Louis, 2B, 5Y, 62

Llored, M., 26

Lochner, Wouter, 3D, 5F

Lodi, Marcello, $6 Z$

Loeff, A., OV

Löhmannsröben, Hans-Gerd, 10

Loicq, Jerome, $4 \mathrm{O}$

Lomanowski, Bartosz, 6V

López Ariste, Arturo, 6S

López, N., OD

López, R. L., 5P

López, V., OD

Lopez-Colino, Fernando, $1 \mathrm{~V}$

Lopez-Morales, Mercedes, 31

Lorente, Nuria P. F., IW

Lormeau, Jean Pierre, $3 Y$

Lou, Zheng, 1D

Lousberg, Gregory P., 1F, 6F

Love, Jonathan, 3D, 44

Lovis, Christophe, $6 \mathrm{Z}$

Löwinger, Tom, 2B

Lowman, Andrew E., OF, 0O, OR

Lown, J. G., 33

Lucero Álvarez, Maribel, 11, 4E, 4F

Luis-Simoes, R., 3K

Lutz, R. D., OV

Ma, Zhenyu, 57

Maartens, Deneys S., 5F

Maciaszek, T., OM

MacLachlan, David G., 27, 28, 2X, 5Q

Madec, F., 26

Magrin, Demetrio, 10, 2Q

Mahadevan, S., 74
Maldonado, X. M., 4D, 5L

Mali, Slavko, $1 \mathrm{~W}$

Maloney, Chris, OL, 3Y

Malvezzi, A. Marco, 2E

Maniscalco, Matthew, 04, 6A

Marafatto, Luca, 10, 2Q

Marco de la Rosa, J., $1 C$

Marcos, Michel, 11, 67

Marinai, M., $2 Y$

Marín-Franch, A., 2H, 2W, 3A

Maroto, Óscar, 6D

Marquart, Thomas, 2B

Martin, Hubert M., OP, OV, OX

Martin, L., OM

Martin, Olivier, 05

Martin, Stefan, 20

Martínez-Delgado, I., 4D, 5L

Martinez-Garcia, M. Sofia, IV

Martín-Fernández, Sergio Gonzáles, 63

Martinis, Lorenzo, 66

Martín-Nuño, Carlos, 6D

Marx, David, 6M

Masa, Jose L., IV

Masi, Silvia, 65

Massone, Giuseppe, 2E

Mathew, Joice, 6W

Mato Martínez, A., 1A

Matsuo, Taro, 61

Matthes, A., 2A

Mawet, Dimitri, 2

Maxwell, Jonathan, $0 Q$

May, Andrew J., 65, 66

McCracken, Kenneth, 31

McCulloch, Mark A., 65, 66

McMuldroch, Stuart, 3l

Mecsaci, A., 16, 60

Mégevand, Denis, 3K, 4L

Meister, A., 16

Melhuish, Simon J., 65, 66

Mende, Stephen B., 40

Mendes de Oliveira, Claudia, 31

Méndez, José A., 2E

Meng, Kai, 48

Meng, Yang, 71

Merrill, C., OV

Middleton, Kevin F., 20, 45

Miller, Alexander D., 6B

Miller, Chris, 09, 11, 69

Miller, Joseph, 31

Miller, Katrina R., 5C

Min, Seong-Sik, 10, 12

Mirabet, E., 62

Mishra, Deepta Sundar, 07

Miyata, Takashi, 18, 5N

Moebius, P., $2 Y$

Mohaupt, M., iN

Molina-Conde, Ignacio, 2B

Molinari, Emilio, $6 Z$

Montalvo, Gabriela, 14, 6C

Monte, Christian, 2B 
Montesanti, R. C., 33

Montgomery, David, 11, 69

Moon, Il-Kwon, 41

Mooney, Tom, 2F

Moore, Christopher Samuel, $2 \mathrm{U}$

Moralejo, B., 22

Morales, R., 62

Mori, Kiyoshi, 18, 5N

Mori, T., IR

Morita, Shin-ya, 25

Moroni, Andrea, 61

Morris, T. J., 27

Moschetti, Manuele, $3 \mathrm{H}$

Motohara, Kentaro, 25

Mottaghibonab, A., 16, 60

Mouillet, D., 26

Mudry, Emeric, 6F

Mueller, Mark, 31

Mueller, Rolf, IW

Muller, Richard E., $3 Z$

Müller, S., 30

Murakami, Naoshi, 6G, 61

Murthy, Jayant, 6W

Myers, Richard M., 6Q

Nagayama, Takahiro, 37

Nakagawa, Hiroyuki, 5T

Nakanishi, Kenshi, $5 Z$

Nannarone, Stefano, 2E

Narayanan, Gopal, 4F

Nash, Reston, 05

Natali, Dario, $6 \mathrm{X}$

Naulin, V., 2W

Navarro, Ramon, 15, $1 \mathrm{~J}$

N'Diaye, M., 26

Neill, D., OX

Nemanich, Robert, $2 \mathrm{~F}$

Nemati, Bijan, 6M

Newman, Kevin, 6L

Nichani, Vijay, 1W, 23

Nicholson, Belinda, 2B

Nielsen, J., 17

Nieuwkoop, Evert, 04

Nieuwland, Govert, 15

Nikzad, Shouleh, $2 \mathrm{U}$

Ninkov, Zoran, 5M, 5U, 5V, 5W, 5X

Nishikawa, Jun, 1R, 6G

Nordsieck, Kenneth H., 3D

Núñez Cagigal, M., 1A

Nürnberg, Frank, OK

O'Donoghue, Darragh, 3D

Oh, Chang-jin, OF, 0O, OR, 41

Oh, Jae Sok, 31

Ohashi, Hirofumi, 25

Ohsaki, Hiroyuki, 18

Ohsawa, Ryou, 18, 5N

Okada, Kazushi, 18, 5N

Okamoto, T., $2 Z$

Okamoto, Yoshiko K., $5 \mathrm{~T}$

Oliva, Ernesto, 2B, 5G

Oliveira, Antonio, 4L
Oliveira, R. M., 78

Olmos Tapia, Arak, 14, 4E

Onaka, Takashi, 5T

Ordway, Mark, 3l

Origlia, Livia, 2B

Origné, A., 26

Orselli, E., 3B

Ortiz, Ricardo, 38

Overtoom, Ton, 04

Ozaki, Shinobu, 25, 2 Z

Paalvast, Sander, 1B

Packham, Christopher, 18, 5T

Padilla Michel, Yazmin, 55

Paetzelt, Hendrik, 3N

Pai, Naveen, IW, 23

Pamplona, T., OM

Pareschi, Giovanni, 13

Pariani, Giorgio, 34, 3H, 4L

Parihar, Padmakar, 07

Park, Byeong-Gon, 31, 41

Park, Chan, 31, 41

Park, Sung-Joon, 31

Park, Won Hyun, 41

Pasanen, Mikko, OQ

Pascal, Sandrine, 2C, 61

Pasquini, Luca, 2B

Patapis, Polychronis, 2M

Patrikeev, Alexey P., 3U

Patrikeev, Vladimir E., 12, 3T, 3U, 46

Patrón, J., 1A

Paufique, Jérôme, 2B

Paxson, Charles, 31

Pech, M., 40

Pelham, Daniel, 3V

Pellegrino, Sergio, $1 \mathrm{~K}$

Pellish, Jonathan A., 5W

Penka, D., 60

Pennec, Yan, 02

Pepe, Francesco, $6 Z$

Pérez, D., 62

Pérez-Calpena, A., 4D, 5L

Pérez de Taoro, Angeles, 63

Pérez-Sánchez, D., 1C

Peschel, T., 30

Petzold, Uwe, 3E

Pham, Thai, 70

Phillips, Andrew C., $2 \mathrm{G}$

Phillips, David F., 3I, $6 Z$

Piazza, D., $2 Y$

Piccirillo, Lucio, 65, 66

Pierce, Robert, 06

Pirnay, Olivier, 47, 6F

Piskunov, Nikolai, 2B

Plummer, David, 3 I

Poberezhskiy, llya, 6M

Podgorski, William, 3I

Poinsignon, $P_{\text {., }} 4 \mathrm{Z}$

Pommerol, A., $2 Y$

Pont, A., 1C

Portaluri, Elisa, 10 
Poulton, Evan, 02

Prada, Francisco, $1 \mathrm{~V}$

Pradal, Fabien, 21

Pragt, Johan H., 20

Prakash, Ajin, 07, 6W

Prida, Joaquín, 6D

Priest, R. E., 33

Prieto, Eric, OM, 4I

Pueyo, Laurent, 2L

Puget, P., 26

Pulwer, Silvio, 55

Qian, Yuan, 1D

Quechol, J. T., OD

Quijada, Manuel A., 5U, 5V

Quintavalla, Martino, 6X

Quirrenbach, Andreas, 1T, 5Q, 62

Radaelli, Paolo, 61

Ragazzoni, Roberto, 10, 2Q

Raisanen, Alan D., 5M, 5U, 5V, 5W

Rakich, Andrew, 41, 45

Ramón, A., 62

Ramos, Eduardo, 6C

Rando, N., 1G

Ratliff, Christopher, $2 \mathrm{G}$

Ratti, F., $1 G$

Rebolo, R., 3K

Redding, David, $1 \mathrm{~K}$

Rees, Phil, 5G

Reffert, Sabine, $5 \mathrm{Q}$

Reichel, S., 2H, 2W, 3A

Reiners, Ansgar, 2B, 4K, 62

Reinlein, C., $1 \mathrm{~N}$

Renotte, Etienne, $4 \mathrm{O}$

Reshetov, Vlad, 02

Rexius, Olga, 3E

Rey, Juerg, 20

Reyes, J., OD

Reynolds, Robert O., 56

Ribas, I., 62

Richter, Matthew J., 5T

Rider, Kodi, 40

Risse, Stefan, OY, 30

Ritucci, A., 3P

Riva, Marco, 3H, 3K, 4L

Robberto, Massimo, 5M, 5U, 5V, 5W

Robertson, D. J., 3M

Rodenhuis, Michiel, 15, 1B

Rodilla, E., 3K

Rodríguez-de Marcos, Luis, 2E

Roloff, V., $2 Y$

Rolt, Stephen, 6V

Romero, Antonio, 6D

Ropert, S., 4W

Rosenthal, Wylie, 41

Rossin, Christelle, 2C, 61

Roth, Martin M., 10, 22

Roure, Océane, OU

Rousing, Andreas W., 2K

Rousing, Andreas, $6 \mathrm{~N}$

Royo, S., 4W
Ruane, Garreth, 2L

Rubiño-Martín, J. A., 63

Ruch, Eric, OU

Rukdee, S., 74

Rulten, C. B., 40

Russchenberg, Tjeerd, 04

Ryan, Daniel, 6N

Sablowski, D. P., 5H

Sachkov, Mikhail, 4C

Saffari, Pouneh, 55

Safonova, Margarita, 6W

Sagolla, Giuseppe, 6N

Sako, Shigeyuki, 18, 5N

Sakon, Itsuki, 5T

Sala, Giuseppe, 3H

Salas, A., OD

Salasnich, B., 26

Salaun, Y., 5P

Salazar, M. F., OD

Sanchez, Justo, $1 \mathrm{~V}$

Sanchez, Patrice, 2C, 61

Sánchez-Argüelles, David, 4F

Sánchez-Blanco, E., 4D, 5L

Sánchez-Capuchino, J., 5P

Sánchez-Carrasco, M. A., 62

Sánchez-de la Rosa, V., 63

Sánchez-Moreno, F. M., 4D, 5L

Sang, B., 30

Santana, S., 3K

Santos, Pedro, 4L

Sarmiento, Luis Fernando, 4K

Sarpotdar, Mayuresh, 6W

Sarugaku, Yuki, $5 Z$

Sasaki, M., $2 Z$

Sasselov, Dimitar, $6 Z$

Sato, S., $2 Z$

Saunders, Will, 5J

Sauvage, J.-F., 26

Savarese, Salvatore, 4P

Sawyer, Kent, 3F

Sawyer, Robert, OK

Sayède, Frédéric, 20, 40

Schier, J. Alan, 3D

Schipani, Pietro, 4P

Schlegel, R., 30

Schloerb, F. Peter, $4 \mathrm{~F}$

Schmälzlin, E., 22

Schmidt, Christof, 2B

Schmoll, J., 40

Schnetler, Hermine, 09, 11, 2X, 67, 69

Schöłz, Gerhard, OK

Schrader, Sigurd, 55

Schumacher, Jean-Marc, 1F, 6F

Schürmann, M., 30

Schuster, Kay, $1 T$

Schwab, Christian, 1T, 29, 74

Schwartz, Timothy A., 5M

Schwinde, S., 30

Scowen, Paul A., 2F, 6B

Sebag, J., OX

xxiv

Proc. of SPIE Vol. $9912991201-24$ 
Seemann, Ulf, 2B

Seery, Bernard, 70

Seifahrt, Andreas, 1P, 1T, 29, 31, 5C

Seifert, W., 62

Selimoğlu, Özgür, 53

Semenov, Aleksandr P., 3T, 3U, 46

Seo, Byoung-Joon, 6M

Seuoka, Stacey R., 6U

Shaklan, Stuart, 2L, 2O, 6H, 6N

Shao, Fei, 79

Sharp, Rob, 17, 64

Shaw, Benjamin, 6V

Sheikh, David A., 39

Shen, Yuran, 5E

Sherwood, Richard E., 35

Shi, Yu-feng, 79

Shimatsu, T., $2 Z$

Sidick, Erkin, 6M

Silva, Catarina, 4L

Simcoe, Robert, $1 \mathrm{X}$

Simoes, Roberto, $1 \mathrm{E}$

Sirbu, Dan, 6L, 6N

Sironi, Giorgia, 13

Smith, David R., 14, 3P, 4E, 4F

Smith, Greg A., OF, 0O, OR

Smith, Michael P., 5B

Sol, H., 40, 4Z

Song, $\mathrm{Ci}, \mathrm{OE}, 3 \mathrm{~W}$

Song, Je Heon, 41

Song, Juan, 79

Sonner, Thomas, $1 \mathrm{E}$

Souccar, Kamal, 14

Soulez, F., 77

Spaleniak, Izabela, J., 27, 28

Spruit, Helma, 04

Stahl, H. Philip, OS

Stark, Daniel, 31

Staszak, Nicholas F., 1W, 23

Steeves, John, 1K, 2O, 6H

Stefánsson, G. K., 74

Stegmeier, Jörg, 2B

Steiner, Joao, 31

Stelter, D., 3M

Stempels, Eric, 2B

Stockman, Yvan, 40

Strachan, J., 5S

Strassmeier, Klaus G., 5H, 50

Strittmatter, P. A., OV, OX

Strydom, Ockert J., 3D, 44, 5F

Stürmer, Julian, 1P, 1T, 29, 5C, 74

Stuik, Remko, 20

Su, Peng, 00

Su, Tianquan, 00

Suc, V., 4W

Sudarikov, Ivan N., 12

Sueoka, Stacey Ritsuyo, 6T, 6U

Sugawara, Jun, OL

Sukegawa, Takashi, 2V

Sun, Weimin, 57

Suresh, Ambily, 6W
Sutherland, Adam P., 1T, 5C

Suzuki, Takeshi, 2V

Szentgyorgyi, Andrew, 3I, 6 Z

Szeto, Kei, 02

Tahtali, Murat, 30

Takahashi, Hidenori, 18, 25

Tala, M., 4W

Tal-Or, Lev, 4K

Tamura, Motohide, 1R, 6G, 61

Tanaka, I., $2 Z$

Tanaka, Y., IR

Taubert, Dieter, 2B

Tayabaly, Kashmira, 13

Taylor, William, 5G

Tecuapetla Sosa, Esteban, 11, 4F

Tenegi, F., 3K

Terao, Yasunori, 25

ter Horst, Rik, $1 \mathrm{~J}$

Terraneo, M., 3P

Teuwen, Maurice, 1A, 1B

Thewissen, Kristof, 1E

Thiele, H., 16, 60

Thomas, N., $2 Y$

Thomson, Mark, $6 \mathrm{H}$

Thomson, Robert R., 27, 28, 2X, 5Q

Threadgold, Timothy M., 35

Thronson, Harley, 70

Todd, S. P., 5S

Tokoro, Hitoshi, 5T

Tomàs, Albert, 6D

Tordo, Sebastien, 2B

Tosh, Ian A., 45

Trager, Scott C., 20, 45, 6D

Travinsky, Anton, 5M, 5U, 5V, 5W

Trines, Robin, 1B

Tubío Araújo, Óscar, 4H

Tuell, Michael T., OP, OV, OX

Tünnermann, Andreas, $3 \mathrm{X}$

Tzile Torres, Carlos, 11, 4F

Uchiyama, Masahito S., 18, 5N

Uchiyama, Mizuho, $5 \mathrm{~N}$

Udry, Stephane, $6 Z$

Underhill, Matthew, 3V

Unser, M., 77

Uomoto, Alan, 31

Uomoto, M., $2 Z$

Vaccarella, Annino, 17, 64

Vallenari, Antonella, 20, 45, 6D

Valsecchi, G., 3P

van Amerongen, Aaldert H., 15

van den Berg, Raoul, $5 \mathrm{~F}$

Vanderbei, Robert, $6 \mathrm{~N}$

van Duffelen, Farian, 09, 11

van Riel, Martijn, 04

Vanzi, L., 74

Vassallo, D., 2Q

Vayssade, Hervé, 2 I

Vaz Cedillo, J. J., 5P

Veach, Todd J., 6B

Vega Reyes, N., 1C, 5P 
Vega-Moreno, A., 63

Veilleux, Sylvain, 10, 71

Venema, Lars, 09, 15, 11

Véran, Jean-Pierre, 05

Vergne, L., $4 \mathrm{Z}$

Vérinaud, Christophe, 6K

Vest, Colin, 17, 64

Vidal-Dasilva, M., 2E

Viera Curbelo, Teodora Aleida, 63

Vigan, A., 26

Vilchez, J., 5L

Viliesid Alonso, Miguel, 11

Vink, Ramon, 15

Viotto, V., 2Q

Visser, Simon, 1E

Vives, Sebastien, 2C, 61

Vlasenko, Oleg, 4C

Vongehr, M., 60

Vorobiev, Dmitry, 5M, 5U, 5V, 5W, $5 \mathrm{X}$

Vuong, Minh V., IW

Wachs, Jordan, 06

Waddell, Patrick, 2T

Walker, David, 3Q

Wallace, J. Kent, $1 \mathrm{~K}$

Waller, Lew, 1W, 23

Walsworth, Ronald L., 3l, 6 Z

Wang, Hairen, ID

Wang, Jianping, 4X, 4Y, 58, 59

Wang, Jin Q., 4J

Wang, Jing, 57

Wang, Wen-cong, 79

Webb, David, 2O, 6H

Weber, Michael, 5H, $5 \mathrm{O}$

Weidmann, Damien, 2X

Weinberger, S. N., OV

Wells, M., $5 \mathrm{~S}$

West, Ray, 5X

West, Steve C., OP, OV, OX

Westerhoff, Thomas, OJ, $\mathrm{OZ}$

Wiid, Eben P., $5 F$

Wildschut, Justin, 04

Wilkinson, Martin, 3D, 5F

William, Jean-Philippe, $0 U$

Wilson, Daniel W., $3 Z$

Wilson, Grant W., 4F

Wimmer, C., 16, 60

Winter, Calvin, 02

Wittmer, Volker, 3E

Witvoet, Gert, 6A

Woche, Manfred, $5 \mathrm{H}, 5 \mathrm{O}$

Wolf, Marsha J., 5B

Wolfs, Fabrice, 47

Woolf, N. J., OX

Wu, Hsing-Yu, 3Q, 48

Wuillaume, Philippe, OU

Xie, Xuhui, OE, 3W

Xin, B., OX

$X \cup$, Chen, OA

Xu, Qiuyun, OA

Yamagata, Yutaka, 25, $2 Z$
Yamaguchi, Jumpei, 5N

Yan, Qi, 57

Yang, Bing, $O E$

Yang, Ho-Soon, 41

Yang, Ji, 1D

Yerli, Sinan Kaan, 73

Yesilyaprak, Cahit, 73

Yoneta, Kenta, 61

Yong, Liu, 79

Yoon, Yang-noh, 41

Younes, Youssef, 20

Young, P. J., 17

Yoxall, B. E., 33

YU, Binbin, OA, OB

Yu, Guoyu, 3Q

$Y U$, Hongbin, $2 F$

Yu, Lin F., 4J

Yu, Young-Sam, 3l

Zamkotsian, Frederic, 34

Zanutta, A., 3B

Zavattini, Lorenzo, 61

Zeitner, U. D., 2A

Zhai, Chao, 1S, 4X, 58, 59, 5A, 5E, 5 I

Zhang, Feifan, $4 X$

Zhang, Haiying, $\mathrm{OA}$

Zhang, Kaiyuan, 5J

Zhang, Yi F., 4J

Zhang, Yu-tu, 79

Zhao, Chunyu, 00, 0R

Zhelem, Ross, 1W, 23

Zheng, Jessica R., 5J

Zheng, Xiao, $3 Q$

Zheng, Yi, OA

Zhou, Hongfei, $4 X$

Zhou, Lin, OE

Zhou, Ping, 00

Zhou, Zengxiang, 4X, 4Y, 58, 59

Zhu, Jing, 1D

Zhu, Tiecheng, 71

Zhu, Ye, 5A

Ziethe, R., $2 Y$

Zimmermann, C., $2 Y$

Zindel, D., $1 G$

Zocchi, F. E., 3P

Zuccaro Marchi, Alessandro, $1 \mathrm{H}$

Zuo, Yingxi, ID

xxvi

Proc. of SPIE Vol. $9912991201-26$ 


\section{Conference Committee}

Symposium Chairs

Colin Cunningham, UK Astronomy Technology Centre (United Kingdom)

Masanori lye, National Astronomical Observatory of Japan (Japan)

Symposium Co-chairs

Allison A. Barto, Ball Aerospace \& Technologies Corporation

(United States)

Suzanne K. Ramsay, European Southern Observatory (Germany)

Conference Chairs

Ramón Navarro, NOVA Optical \& Infrared Instrumentation Group at ASTRON (Netherlands)

James H. Burge, College of Optical Sciences, The University of Arizona (United States)

Conference Program Committee

Daniel R. Blanco, MMT Observatory (United States)

Myung Kyu Cho, National Optical Astronomy Observatory

(United States)

V. Alfonso Feria, Jet Propulsion Laboratory (United States)

Virginia G. Ford, Thirty Meter Telescope Observatory Corporation

(United States)

Roland Geyl, REOSC (France)

Roger Haynes, Leibniz-Institut für Astrophysik Potsdam (Germany)

Emmanuel Hugot, Laboratoire d'Astrophysique de Marseille (France)

Huub Janssen, Janssen Precision Engineering B.V. (Netherlands)

Ralf Jedamzik, SCHOTT AG (Germany)

Matthew A. Kenworthy, Leiden Observatory (Netherlands)

Hélène T. Krol, CILAS (France)

David M. Montgomery, UK Astronomy Technology Centre (United Kingdom)

Andrew T. Sarawit, Simpson Gumpertz \& Heger Inc. (United States)

Robert R. Thomson, Heriot-Watt University (United Kingdom)

Jinxue Wang, Raytheon Space \& Airborne Systems (United States) 


\section{Session Chairs}

1 Atmospheric Compensation

Matthew A. Kenworthy, Leiden Observatory (Netherlands)

2 Segment Mirror Technologies

Myung Kyu Cho, National Optical Astronomy Observatory (United States)

3 Optical Fabrication

Roland Geyl, REOSC (France)

4 Materials

Ralf Jedamzik, SCHOTT AG (Germany)

5 Large Optics Manufacturing

Roland Geyl, REOSC (France)

6 Test and Metrology I

Virginia G. Ford, Thirty Meter Telescope Corporation (United States)

7 Test and Metrology II

Ramón Navarro, NOVA Optical Infrared Instrumentation Group at ASTRON (Netherlands)

James H. Burge, College of Optical Sciences, The University of Arizona (United States)

8 Technologies for Cryogenic Instruments

Huub Janssen, Janssen Precision Engineering B.V. (Netherlands)

9 Telescope Structures and Domes

Andrew T. Sarawit, Simpson Gumpertz \& Heger Inc. (United States)

10 Active Instruments (Active Structures, Active Optics)

Emmanuel Hugot, Laboratoire d'Astrophysique de Marseille (France)

Poster Previews

Ramón Navarro, NOVA Optical Infrared Instrumentation Group at ASTRON (Netherlands)

11 Optical Fibers and Positioners I

Roger Haynes, Leibniz-Institut für Astrophysik Potsdam (Germany)

12 Optical Fibers and Positioners II

Roger Haynes, Leibniz-Institut für Astrophysik Potsdam (Germany) 
13 Multi Object Spectroscopy

Robert R. Thomson, Heriot-Watt University (United Kingdom)

14 Slit Spectroscopy and Image Slicers

Roland Geyl, REOSC (France)

15 Coatings, Filters and Gratings I

Hélène T. Krol, CILAS (France)

Poster Session: Coronography and High Contrast Imaging

Emmanuel Hugot, Laboratoire d'Astrophysique de Marseille (France)

16 Coatings, Filters and Gratings II

Hélène T. Krol, CILAS (France)

17 Coronography and High Contrast Imaging

Matthew A. Kenworthy, Leiden Observatory (Netherlands)

Closing and Award Ceremony

Ramón Navarro, NOVA Optical Infrared Instrumentation Group at ASTRON (Netherlands) 
Proc. of SPIE Vol. $9912991201-30$

Downloaded From: https://www.spiedigitallibrary.org/conference-proceedings-of-spie on 25 Apr 2023 Terms of Use: https://www.spiedigitallibrary.org/terms-of-use 


\section{Introduction}

Ever since the invention of the telescope, new technologies have been used in astronomy to improve observations and to eventually better understand our position in the universe.

For forty years, SPIE has organized conferences on astronomical telescopes and instrumentation. These events grew to become huge symposia with specialized parallel conferences on all major instrumental areas, such as space- and groundbased telescopes, detectors, interferometers, and adaptive optics. The increasing complexity of astronomical instrumentation resulted in the need for yet another conference dedicated to the enabling technologies. This conference is now called "Advances in Optical and Mechanical Technologies for Telescopes and Instrumentation", and was held for the first time in 2002 with 47 contributions, as part of the SPIE symposium of several conferences on astronomical telescopes and instrumentation. In 2016 the number of papers has increased to over 250. Six full days were necessary to schedule about a third of the submitted contributions for oral presentations. The other contributions were presented as poster presentations. Such a full conference week can be exhausting. The readers of these proceedings are in a more comfortable position: they can take their time to study the interesting and well written contributions from scientists, engineers and technologists from laboratories all over the world. However, they will of course miss out on the presentations, which often contain additional details and graphs and an increasing number of videos.

This volume documents the fabrication process, including test and metrology, of the optical components for LSST (United States) and the upcoming generation of extremely large telescopes. The instrumentation for this new generation of telescopes has become more complex, depending on extreme aspheres, active and adaptive optics. Photonic techniques used in optical fibres and miniaturised mechanisms for positioners allow larger surveys with multi object spectrographs. Spectroscopy benefits from improvements in volume phase holographic gratings and immersed grating techniques. New mechanisms and optical mounts were presented for atmospheric dispersion correction. High-contrast imaging can be achieved with optical retarder filters. And there is much more to explore in these proceedings.

We hope that the readers find these proceedings exciting, and that they stimulate ideas for their own research. 
We look forward to seeing you at the next conference on "Advances in Optical and Mechanical Technologies for Telescopes and Instrumentation" in Austin, Texas (United States) in the summer of 2018.

Ramón Navarro

James H. Burge 